Article

\title{
Comparative Analysis on the Structure and Properties of Iron-Based Amorphous Coating Sprayed with the Thermal Spraying Techniques
}

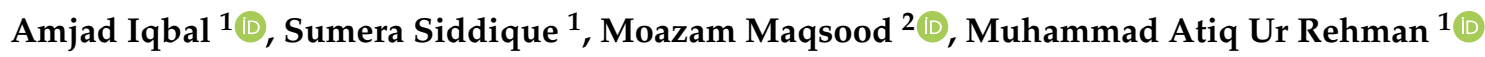 \\ and Muhammad Yasir ${ }^{1, *(1)}$ \\ 1 Department of Materials Science and Engineering, Institute of Space Technology, Islamabad Highway 1, \\ Islamabad 44000, Pakistan; amjadiqbalfalak@gmail.com (A.I.); sumera.siddique@hotmail.com (S.S.); \\ atique1.1@hotmail.com (M.A.U.R.) \\ 2 Department of Electrical Engineering, Institute of Space Technology, Islamabad Highway 1, Islamabad 44000, \\ Pakistan; moazam.maqsood@ist.edu.pk \\ * Correspondence: muhammad.yasir@mail.ist.edu.pk or muhammadyasir85@gmail.com
}

Received: 23 September 2020; Accepted: 18 October 2020; Published: 21 October 2020

check for updates

\begin{abstract}
Iron-based amorphous coatings are getting attention owing to their attractive mechanical, chemical, and thermal properties. In this study, the comparative analysis between high-velocity oxy-fuel (HVOF) and atmospheric plasma (APS) spraying processes has been done. The detailed structural analysis of deposited coatings were studied by scanning electron microscopy (SEM) and X-ray diffraction (XRD). Mechanical and electrochemical properties were investigated by using micro-Vickers hardness testing, pin-on-disc tribometry and potentiodynamic analysis. The microstructure comparison revealed that HVOF-coated samples had better density than that of APS. The porosity in APS-coated samples was 2 times higher than that of HVOF-coated samples. The comparison of tribological properties showed that HVOF-coated samples had 3.9\% better hardness than that of coatings obtained via APS. The wear test showed that HVOF-coated samples had better wear resistance in comparison to APS coatings. Furthermore, the potentiodynamic polarization and electrochemical impedance spectroscopy showed that the HVOF-coated samples had better corrosion resistance in comparison to APS-coated samples.
\end{abstract}

Keywords: iron-based amorphous coatings; wear resistance; corrosion resistance; atmospheric plasma spraying; high-velocity oxy-fuel spraying

\section{Introduction}

Bulk metallic glasses (BMGs) are considered widely as one of the best coating materials due to their ultra-high strength, high hardness, large elastic strain limits, hydrophobicity, magnetic properties, good corrosion and wear resistance, thermal stability, relatively low cost, and good glass formability (GFA) [1-3]. However, BMGs applications are limited due to the innate brittleness at room temperature. In order to cope with this problem, BMG-based composite coatings and iron-based amorphous coatings are fabricated by thermal spraying techniques, which is an attractive approach [4]. The thermal spraying processes, high-velocity oxy-fuel (HVOF) and atmospheric plasma spray (APS) have been widely used to fabricate amorphous coatings due to their low cost, flexibility regarding substrate material, relatively fast cooling rate, and high deposition rate [5,6].

The Defense Advanced Research Projects Agency of United States (DARPA) in 2003 started high-performance corrosion resistant (HPCR) materials project in which they had tested many HPCR alloys for the defense applications. Two systems with iron-based alloy compositions of $\mathrm{Fe}_{48} \mathrm{Mo}_{14} \mathrm{Cr}_{15} \mathrm{Y}_{2} \mathrm{C}_{15} \mathrm{~B}_{6}$ (SAM1651) and $\mathrm{Fe}_{49.7} \mathrm{Cr}_{17.7} \mathrm{Mn}_{1.9} \mathrm{Mo}_{7.4} \mathrm{~W}_{1.6} \mathrm{~B}_{15.2} \mathrm{C}_{3.8} \mathrm{Si}_{2.4}$ (SAM2X5) were selected 
on the basis of their performance in aggressive environments compared to other materials [7]. Huang et al. found that Fe-based amorphous BMGs could work at high temperatures (i.e., 300-571 K) and had excellent wear resistance compared to that of the traditional alloys, and BMG systems [8]. Rui et al. experimented with $\mathrm{Mo}_{7.4} \mathrm{~W}_{1.6} \mathrm{~B}_{15.2} \mathrm{C}_{3.8} \mathrm{Si}_{2.4}$ (material composition employed because of its high neutron-absorbing ability from boron atom) and found excellent wear and corrosion resistance in the underground environment (deep burial of spent nuclear fuel storage vessels in the earth) due to "plugging effect" [8,9]. Lu Xie reported that iron-based amorphous coating exhibited low wear rate and higher hardness when the level of porosity was low and amorphous content of the coating was higher. Recently, Lei Qiao et al. fabricated iron-based amorphous coatings by optimizing the HVOF parameters and investigated that iron-based coating were more corrosion resistant compared to hard chromium coating due to their dense structure, lower porosity, and amorphous phase [10].

Atmospheric plasma spray (APS) technique is being widely used for iron-based amorphous/ nanocrystalline composite coatings in the industries. Anil et al. fabricated low chromium-based nanocrystalline composite coatings by optimizing APS coatings parameters and found that coating obtained at high power plasma exhibited higher abrasive wear and corrosion resistance with the increased hardness [11]. C. Zhang et al. fabricated superhydrophobic metallic coatings by depositing iron-based amorphous alloy. They studied that the surface roughness was a key factor during transformation from hydrophilic to hydrophobic character of the coatings. They found that if the average surface roughness of the coating was greater than $9 \mu \mathrm{m}$, it was hydrophobic; and if the average surface roughness was less than $5.6 \mu \mathrm{m}$, it was hydrophilic. The globular structure formation via thermal spraying indicated that this type of iron-based coating had good adhesion strength [12].

The study of above literature shows that iron-based amorphous coating has outstanding properties, and thermal spraying is the method of choice to fabricate these coatings. In the past, the comparative study between APS and HVOF has rarely been discussed and both techniques have their own characteristics. The main objective of this research work is to study the difference between mechanical and chemical properties of iron-based amorphous coating sprayed by two different thermal spraying techniques. In this study, iron-based alloy with $\mathrm{Fe}_{48} \mathrm{Mo}_{14} \mathrm{Cr}_{15} \mathrm{Y}_{2} \mathrm{C}_{15} \mathrm{~B}_{6}$ composition was deposited via APS and HVOF techniques. The effect of deposition parameters on mechanical properties (Wear and Hardness) and corrosion resistance was investigated. Finally, the results were summarized and compared with the available literature.

\section{Materials and Methods}

Low-carbon steel was used as a substrate. The steel sample was sectioned into $10 \times 10 \times$ $1 \mathrm{~cm}^{3}$ - sized specimens using a disc cutter. The substrate was degreased using acetone, and afterwards, air spraying was done to remove corrosion products and dust particles from the surface. To increase the roughness of the substrate, sand blasting was done at $0.3 \mathrm{MPa}$ followed by air drying. The higher roughness of the substrate allowed the development of strong mechanical bonding between the coating and the substrate. The commercially available powder having composition $\mathrm{Fe}_{48} \mathrm{Cr}_{15} \mathrm{Mo}_{14} \mathrm{C}_{15} \mathrm{~B}_{6} \mathrm{Y}_{2}$ was used as spraying material. The commercially available SAM1651 amorphous alloys (Beijing Thermal Sun Spraying Manufacturers, Beijing, China) was used due to their outstanding properties in harsh environments. Before initiating the thermal spraying process, powder heating was done at $150{ }^{\circ} \mathrm{C}$ for $2 \mathrm{~h}$. The heating of the powders at lower temperatures is usually done for moisture removal, for better performance during thermal spraying. SX-80 APS (Sanxin Metal S\&T, Guangzhou, China) and SX-5000 HVOF (Sanxin Metal S\&T, Guangzhou, China) spray equipment were employed to spray iron-based amorphous coatings. In case of APS, argon at $0.7 \mathrm{psi}$ and $120-130 \mathrm{~L} \mathrm{~min}^{-1}$ was used as primary gas, while hydrogen at $0.7 \mathrm{psi}$ and $30-35 \mathrm{~L} \mathrm{~min}^{-1}$ was used as secondary gas. To prevent overheating of the spray gun, cold water was introduced through chiller $\left(\right.$ at $\left.-17^{\circ} \mathrm{C}\right)$, which maintained overall temperature of the gun. Three major gases used in HVOF equipment were Nitrogen $\left(\mathrm{N}_{2}\right)$ as powder feeder gas, propane $\left(\mathrm{C}_{3} \mathrm{H}_{8}\right)$, and oxygen for combustion process. The process parameters for APS and HVOF are presented in Tables 1 and 2. Coated samples obtained by APS and HVOF were cut into 
$1 \times 1 \times 1 \mathrm{~cm}^{3}$ specimens via wire arc cutting. Afterwards, coated samples were ground and polished to obtain scratch-free surface. The microstructure at the surface and cross-section were examined by scanning electron microscope (SEM) Mira 3 TESCAN, Brno, Czech Republic at 10 KV.

Table 1. Atmospheric plasma (APS) spraying parameters.

\begin{tabular}{ccccc}
\hline Voltage & Current & Feeding Rate & Spray Distance & Power \\
\hline $55-60 \mathrm{~V}$ & $200-850 \mathrm{~A}$ & $30 \mathrm{~g} \mathrm{~min}^{-1}$ & $200 \mathrm{~mm}$ & $35 \mathrm{KW}$ \\
\hline
\end{tabular}

Table 2. High-velocity oxy-fuel (HVOF) spraying parameters.

\begin{tabular}{ccccc}
\hline Propane Flow & Oxygen Flow & Feeding Rate & Spray Distance & Compressed Air \\
\hline $25 \mathrm{~L} \mathrm{~min}^{-1}$ & $15 \mathrm{~L} \mathrm{~min}^{-1}$ & $30 \mathrm{~g} \mathrm{~min}^{-1}$ & $300 \mathrm{~mm}$ & $0.5 \mathrm{MPa}$ \\
\hline
\end{tabular}

Figure 1a shows the SEM image of the iron-based amorphous powder used in this study. It was observed that the particles are randomly distributed with good fluidity (Figure 1a). The observed morphology of the iron-based amorphous powder shows that it can produce good quality coatings and can easily pass through a spray gun of both techniques. The particles size distribution was calculated by Mastersizer 3000, Malvern Instrument LTD., Malvern, UK. The particle size analysis of SAM1651 exhibited the particle size in the range of $20-70 \mu \mathrm{m}$. The majority of the particles are in the range of 20-50 $\mu \mathrm{m}$. This range is represented in graphical form in Figure 1b. The structure of the deposited coatings was investigated by X-ray diffractometer (XRD) GNR Analytical Instrument Group Explorer, Novara, Italy using 2-theta range of $20^{\circ}-80^{\circ}$ with a step size of $0.01^{\circ}$. The results are shown in Figure $1 \mathrm{c}$, and show the amorphous nature of the powder. Thermal stability of the coatings was investigated by Mettler Toledo (Columbus, OH, USA) Differential scanning calorimetry (DSC) 1-star system. DSC was done at the scanning rate of $10 \mathrm{~K} / \mathrm{min}$ and up to $900{ }^{\circ} \mathrm{C}$.
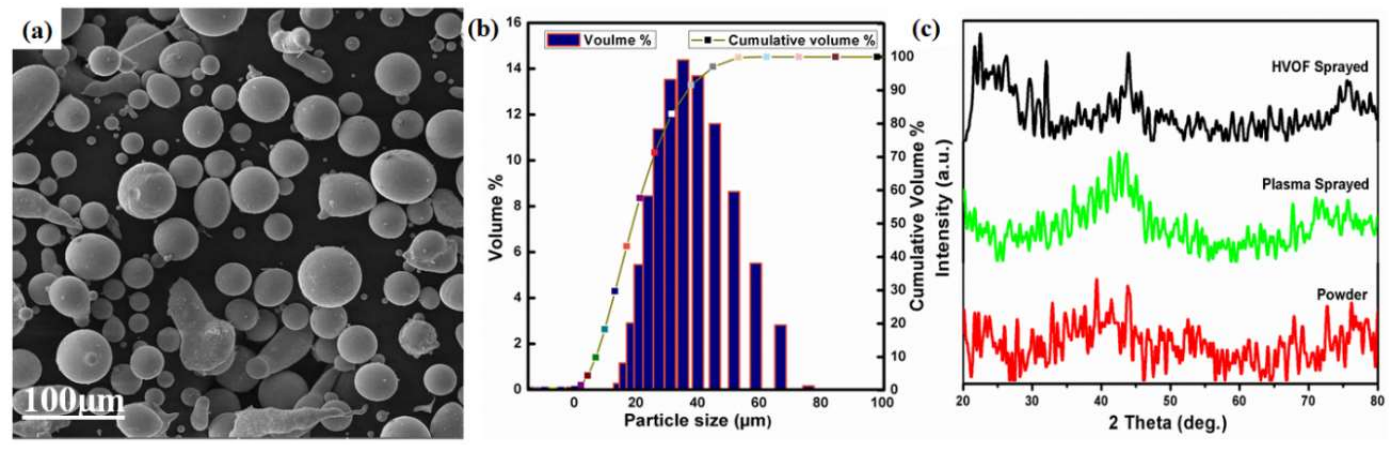

Figure 1. (a) SEM micrograph of $\mathrm{Fe}_{48} \mathrm{Mo}_{14} \mathrm{Cr}_{15} \mathrm{Y}_{2} \mathrm{C}_{15} \mathrm{~B}_{6}$ powder, (b) particle size distribution of spray powder, (c) XRD analysis of powder and coatings.

The micro-Vickers hardness test was done by Micro-Vickers Nbk Nabeya VLS 3858 apparatus, Seki City, Japan. Corrosion studies were done by using potentiodynamic polarization and electrochemical impedance spectroscopy (EIS) by the Parstat 3000a-Dx system from Princeton Applied Research, Oak Ridge, TN, USA. Corrosion studies were done by immersing the coatings in $3.5 \mathrm{wt} . \%$ $\mathrm{NaCl}$ at room temperature. The polarization curves were plotted at the scan rate of $3 \mathrm{mV} \mathrm{s}^{-1}$, in the potential range from $\mathrm{E}_{\mathrm{corr}}-500 \mathrm{mV}$ to $\mathrm{E}_{\mathrm{corr}}+500 \mathrm{mV}$. Impedance measurements were carried out at the corrosion potential after $10 \mathrm{~min}$ stabilization of the open circuit potential in the frequency range of $10 \mathrm{mHz}-10,000 \mathrm{~Hz}$. The electrochemical impedance spectroscopy (EIS) results are presented as Nyquist and Bode plots. All of the experiments were repeated at least three times.

Wear studies were done using a Pin-on-disk Microtest Tribometer MT series, Barcelona, Spain at a load of $10 \mathrm{~N}$ under ambient temperature conditions. A diamond indenter of $2 \mathrm{~mm}$-diameter was used 
as counter body. The coated sample disc was rotated at a defined speed, while a fixed diamond indenter was pressed perpendicularly onto the disc's surface. A sliding speed of $15 \mathrm{~cm} / \mathrm{s}$ was applied, until a total sliding distance of $750 \mathrm{~m}$ was achieved. The coefficient of friction (COF) was recorded continuously during the experiment. The wear volume was calculated from the surface profile traces recorded across the wear track perpendicularly to the sliding direction using a profilometer (Sensofar PLu neox, Terrassa, Spain).

\section{Results and Discussion}

\subsection{Morphological Analysis}

Figure 2a shows the SEM image at the cross-section of the steel sample coated with iron-based amorphous powder using APS technique. It can be observed that the coating thickness obtained via APS is $\sim 316 \mu \mathrm{m}$. The cross-section of HVOF-coated sample can be seen in Figure $2 b$, which reveals a coating thickness of $\sim 302 \mu \mathrm{m}$. Moreover, it can be seen in Figure 2c that the iron-based amorphous coatings obtained by APS are porous and relatively less compact in comparison to the coatings obtained via HVOF (Figure 2d). The reason could be that HVOF strongly fused the powder on the surface of substrate while APS showed relatively less fusion of the powder. This is due to high temperature of plasma jet and low velocity of accelerated particles in APS. From the cross-sectional images (Figure 2), it can be concluded that high coating density is achieved in case of HVOF. Relatively higher coating thickness and low coating density is obtained via APS, which may be due to the incomplete fusion. The speed of sprayed particles in APS is less than that in HVOF, that is why particles attain more time of flight, which may lead to relatively higher oxidation at the interphase in APS $[13,14]$. The composition and thickness of the coatings obtained via HVOF and APS were optimized by using the "trial-and-error approach", SEM images taken at the interface of both the coatings revealed that the interface obtained via HVOF is smoother compared to the coatings obtained via APS (Figure 2c,d). The APS-sprayed coatings are irregular because of the presence of many "unmelted iron-based amorphous powder particles".
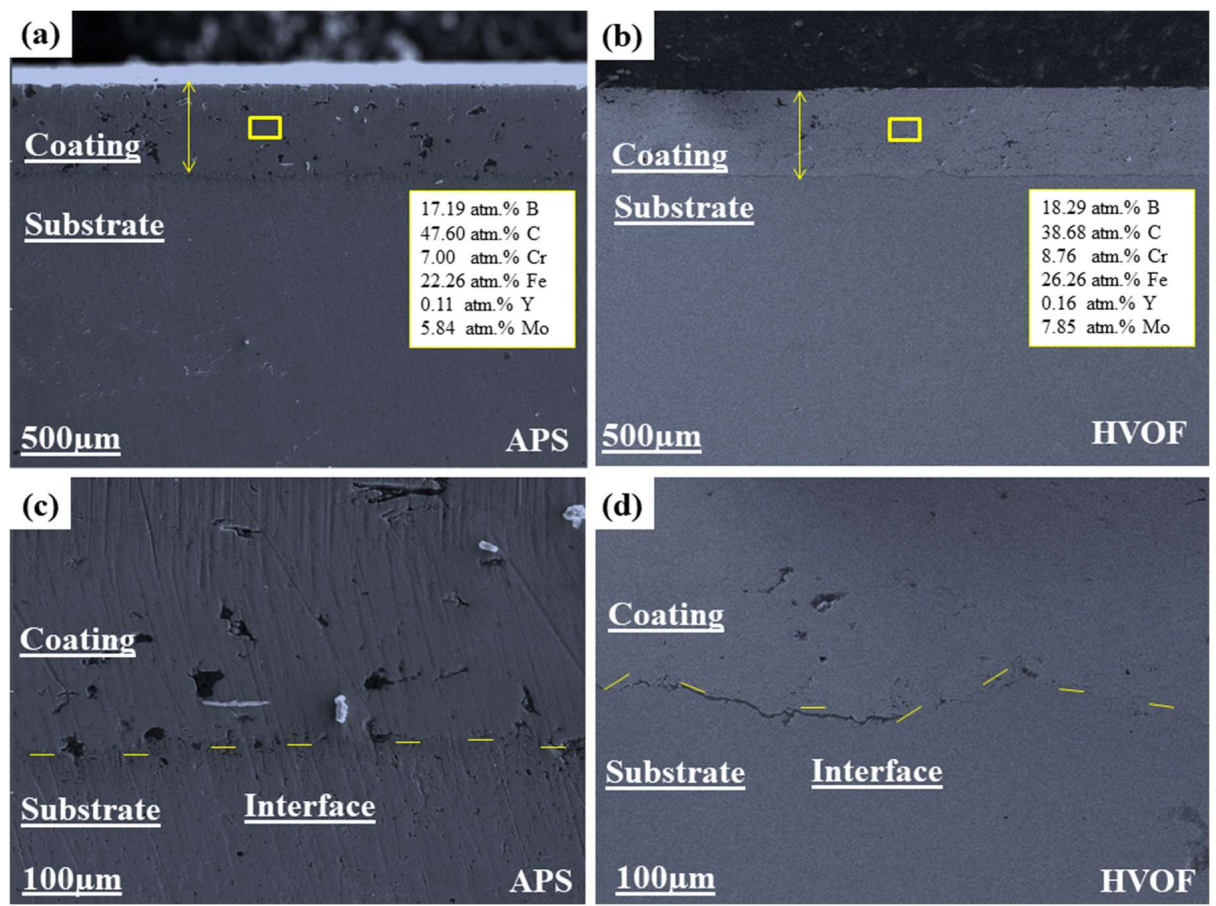

Figure 2. (a) Cross-section of APS-coated sample. (b) Cross-section of HVOF-coated sample, the rectangles in Figure 2a,b show the EDS analysis. (c) Interface in APS-sprayed coating. (d) Interface in HVOF-sprayed coating. 
The calculated porosity level through ImageJ Software was $2.9 \%$ in APS, while for HVOF it was $0.7 \%$. The porosity measurement is the average of calculations made on three SEM images taken from the coating surface.

\subsection{Phase Analysis of the Coating}

Figure 1 shows the XRD patterns for $\mathrm{Fe}_{48} \mathrm{Cr}_{15} \mathrm{Mo}_{14} \mathrm{C}_{15} \mathrm{~B}_{6} \mathrm{Y}_{2}$ powder and coatings obtained via HVOF and APS. XRD analysis exhibits the broad hump between $30^{\circ}-50^{\circ}$, which indicates that the structure of the coatings obtained via HVOF and APS is partially amorphous $[15,16]$. Diffraction pattern of sprayed coating and SAM1651 powder do not show any significant diffraction peak, which confirms the amorphous behavior of the coatings (obtained by HVOF and APS) and powder system (Figure 1c).

Iron-based amorphous coatings are thermally stable. Lu Xie et al. [13] investigated the amorphous content of $\mathrm{Fe}_{48} \mathrm{Mo}_{14} \mathrm{Cr}_{15} \mathrm{Y}_{2} \mathrm{C}_{15} \mathrm{~B}_{6}$ sprayed via APS and HVOF. The amorphous content for APS was $79.39 \%$ with the higher porosity (2.5\%) in coating; while for HVOF the amorphous content was $85.26 \%$ with lower porosity $(1.9 \%)$.

\subsection{Corrosion Studies}

\subsubsection{Potentiodynamic Polarization Scan}

Electrochemical corrosion behavior of coatings was evaluated in 3.5 wt. $\% \mathrm{NaCl}$. Potentiodynamic polarization curves of bare steel substrate and coatings obtained by HVOF and APS are presented in Figure 3a. The current density $\left(\mathrm{I}_{\text {corr }}\right)$ from the anodic and cathodic branches for iron-based amorphous coatings was significantly lower than that of the bare one-almost 4 orders of magnitude systematically shifted down the current density direction for iron-based amorphous coatings obtained via HVOF; and 20 orders of magnitude for the iron-based amorphous coatings obtained via APS (Table 3).
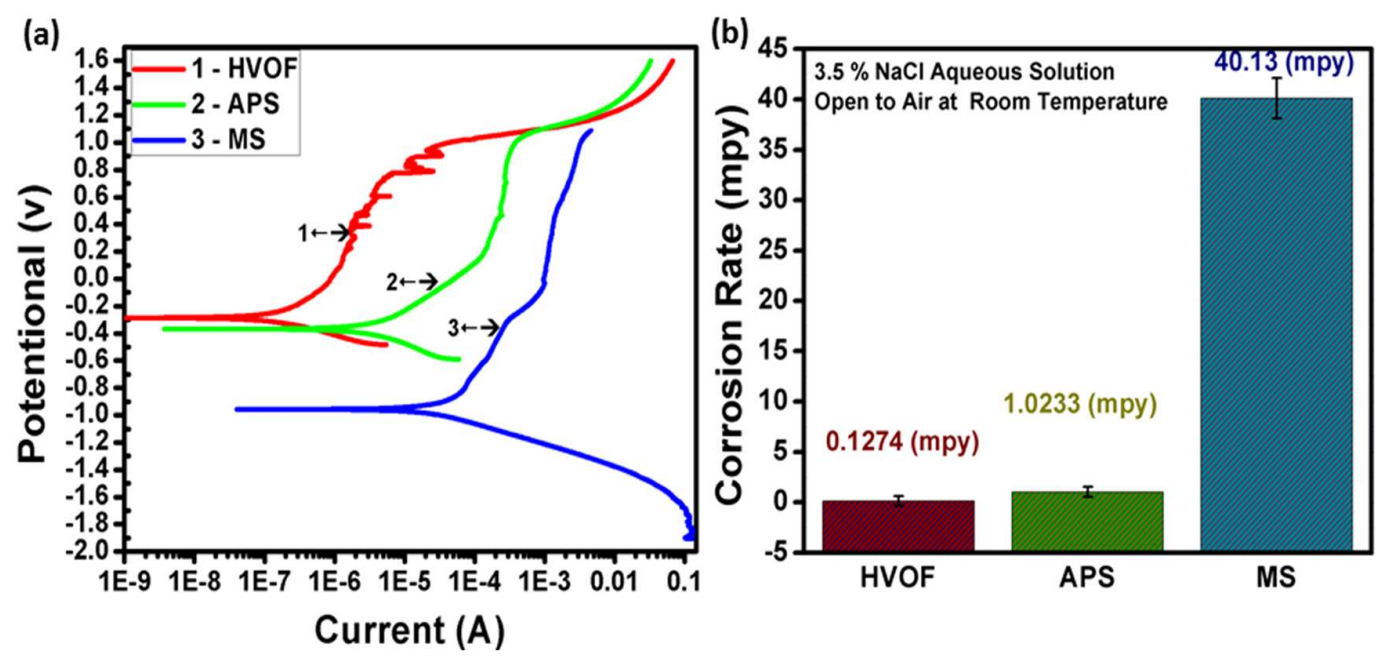

Figure 3. Corrosion analysis. (a) Potentiodynamic polarization curves. (b) Comparison of corrosion rate.

Table 3. Potentiodynamic result.

\begin{tabular}{cccc}
\hline Bare and Coated Samples & $\mathbf{E}_{\text {corr }}(\mathbf{m V})$ & $\mathbf{i}_{\text {corr }}\left(\mathbf{n A} / \mathbf{c m}^{\mathbf{2}}\right)$ & Corrosion Rate $(\mathbf{m p y})$ \\
\hline APS & $-364.563 \mathrm{mV}( \pm 0.50 \%)$ & $954.144 \mathrm{nA}( \pm 0.50 \%)$ & $1.0233( \pm 0.50 \%)$ \\
HVOF & $-282.065 \mathrm{mV}( \pm 0.25 \%)$ & $118.793 \mathrm{nA}( \pm 0.25 \%)$ & $0.1274( \pm 0.25 \%)$ \\
Mild Steel Substrate & $-0.957 \mathrm{~V}( \pm 0.25 \%)$ & $46.7 \mu \mathrm{A}( \pm 0.25 \%)$ & $40.13( \pm 0.25 \%)$ \\
\hline
\end{tabular}

Table 3 presents the values of corrosion potentials ( $\left.E_{c o r r}\right)$ and corrosion current density (Icorr) for iron-based amorphous coatings in comparison to the bare mild steel (MS) substrate. 
It was also observed that both cathodic and anodic branches of iron-based amorphous coatings obtained by both techniques exhibited similar steepness and near-linear Tafel behavior at the potential range of $\pm 50 \mathrm{mV}$ related to the corrosion potential ( $\left.\mathrm{E}_{\mathrm{corr}}\right)$. The stable passive region was observed in both types of coated samples, which demonstrated that the stable oxide layer was developed and protected from further corrosion. The values of $\mathrm{I}_{\mathrm{corr}}$ and $\mathrm{E}_{\mathrm{corr}}$ can be easily compared with each other in Table 3 to distinguish the anticorrosion properties of the coatings from the steel substrate. The curve oscillation of coatings fabricated by HVOF was recorded during the measurement in all samples. Therefore, the oscillation was not caused by the failure of measurement, but might be due to the very low currents generated by the current resolution of the equipment. The order of $\mathrm{E}_{\text {corr }}$ values in Table 3 with respect to bare steel, HVOF coatings, and APS coatings is APS-coated $>$ HVOF-coated $>$ bare MS; whereas the values of the corrosion current density $\left(\mathrm{I}_{\text {corr }}\right)$ could be ranked in an opposite way as APS-coated $<$ HVOF-coated $<$ bare MS. Therefore, the anticorrosion properties of all the samples could be ranked as follows: APS-coated $>$ HVOF-coated $>$ bare MS.

The corrosion rate of mild steel reduced from 40 mils per year (mpy) to $1.0233-0.1274$ mpy by APS and HVOF, respectively. The comparative corrosion rate of APS- and HOVF-coated specimen is displayed in Figure $3 b$, which indicates that the corrosion rate of APS is higher than HVOF. The passive region of HVOF is larger than APS, which reveals stability of passive layer to resist corrosion. APS-sprayed samples are porous in nature, while HVOF has compact and the least-porous surface. The level of porosity is an important factor, as it intensely promotes an active potentiodynamic layer on the surface and suppresses the formation of a strong passive layer [17]. If both the coated samples are compared, it is much easier for chloride ions to break the passive region in plasma-sprayed samples and start corrosion.

Ma et al. proposed that corrosion in SAM1651-coated samples occur (i) where oxide concentration is high, (ii) in a portion containing microdefects and area with least thickness, and (iii) where many interphases destabilize the passive film. After corrosion testing, SEM images (Figure 4) were taken from the corroded surface, which indicated localized corrosion attacks on the surface by pitting corrosion. The initiation of pitting occurs at the interface of chromium-depleted and chromium-rich zones [18]. Surrounding electrolytes act as the cathode while the coated surface acts as an anode, where metal gets oxidized.
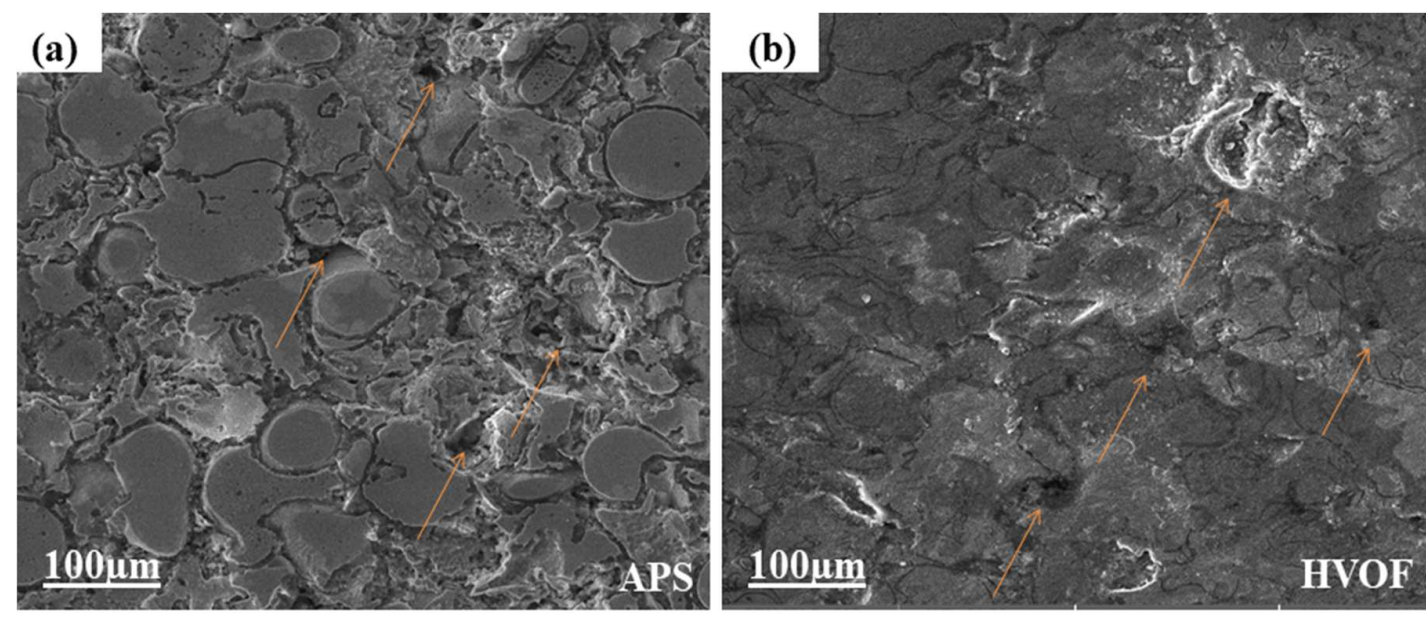

Figure 4. SEM images showing the morphology of APS (a) and HVOF coating (b) after potentiodynamic polarization. The arrowheads indicate a corroded portion on the surface.

The chemical oxidation reaction occurs for $\mathrm{Fe}, \mathrm{Mo}$, and $\mathrm{Cr}$, with the help of dissolved oxygen in the electrolyte. The size difference between $\mathrm{Cr}$ and Mo promotes amorphous properties. On the other side, $\mathrm{Cr}_{x} \mathrm{O}_{y}$ and $\mathrm{Mo}_{x} \mathrm{O}_{y}$ ( $x$ and $y$ are variable valences) are formed which protect the surface from further corrosion. Molybdenum forms tetravalent oxide, $\mathrm{MoO}_{4}$, which promotes the development 
of chromium oxide where it is actively depleted. Molybdenum tetravalent oxide makes a strong hindrance to the active dissolution of chromium oxide; as a result, an excellent passive film is developed on the surface [19]. Iron, being the major element in SAM1651 composition, forms its oxide in the form of ferric/ferrous. The favorable oxides of iron mentioned in literature are lepidocrocite $(\gamma-\mathrm{FeOOH})$, maghemite $\left(\gamma-\mathrm{Fe}_{2} \mathrm{O}_{3}\right)$, and akaganeite $(\beta-\mathrm{FeOOH})$; among these, maghemite is quite a stable oxide. The active process of corrosion continues even if iron oxide layer is formed. The corrosion rust formed by iron is unstable in air and moist environments [11,20].

Figure $4 \mathrm{a}, \mathrm{b}$ shows the morphologies of iron-based amorphous coating after potentiodynamic polarization from $-1 \mathrm{~V}$ to $+1.6 \mathrm{~V}$ under $1 \mathrm{~V} / \mathrm{s}$ scanning rate. Zhang et al. reported higher porosity with least oxygen content, higher roughness, and increase contact angle of iron-based amorphous system gives better corrosion resistance than other bulk metallic glasses [21].

\subsubsection{Electrochemical Impedance Spectroscopy}

Figure 5 shows electrochemical impedance spectroscopy (EIS) results, which are used to predict coating quality by the use of resistance, capacitance, and fit-data in proper circuit model. The corrosive ions in an electrolyte initiate some penetration and make defects in the coatings layer. $R(C R)$ circuit was predicted for EIS data of APS and HVOF via Zsim 3.20 software. Different circuits have been applied to check the correct matching to our sample's results. The circuit $R_{S}\left(Q_{1}\left(R_{1}\left(Q_{2} R_{2}\right)\right)\right)$ was suitable to resultant EIS results. The Nyquist plot for large diameter of the curves indicates higher resistance. In Figure 5, EIS predicts that the largest diameter is shown by HVOF Nyquist plot (a), the higher impedance is shown by HVOF Bode plot (b), and the higher phase angle for HVOF by the phase angle plot (c). Figure 5c shows that there is a capacitance loop for APS and HVOF. The diameter of this capacitance loop is responsible for anticorrosion property. It is revealed that sodium chloride electrolyte is unable to completely attack on the substrate. It is commonly observed the large area of Nyquist plot curve shows more resistant to corrosion. The plot describes a charge-transfer reaction in the passivity of the curve. EIS analysis suggests that there is a bilayer structure of passive film, and elimination of passive film occurs due to aggressive environment [21].
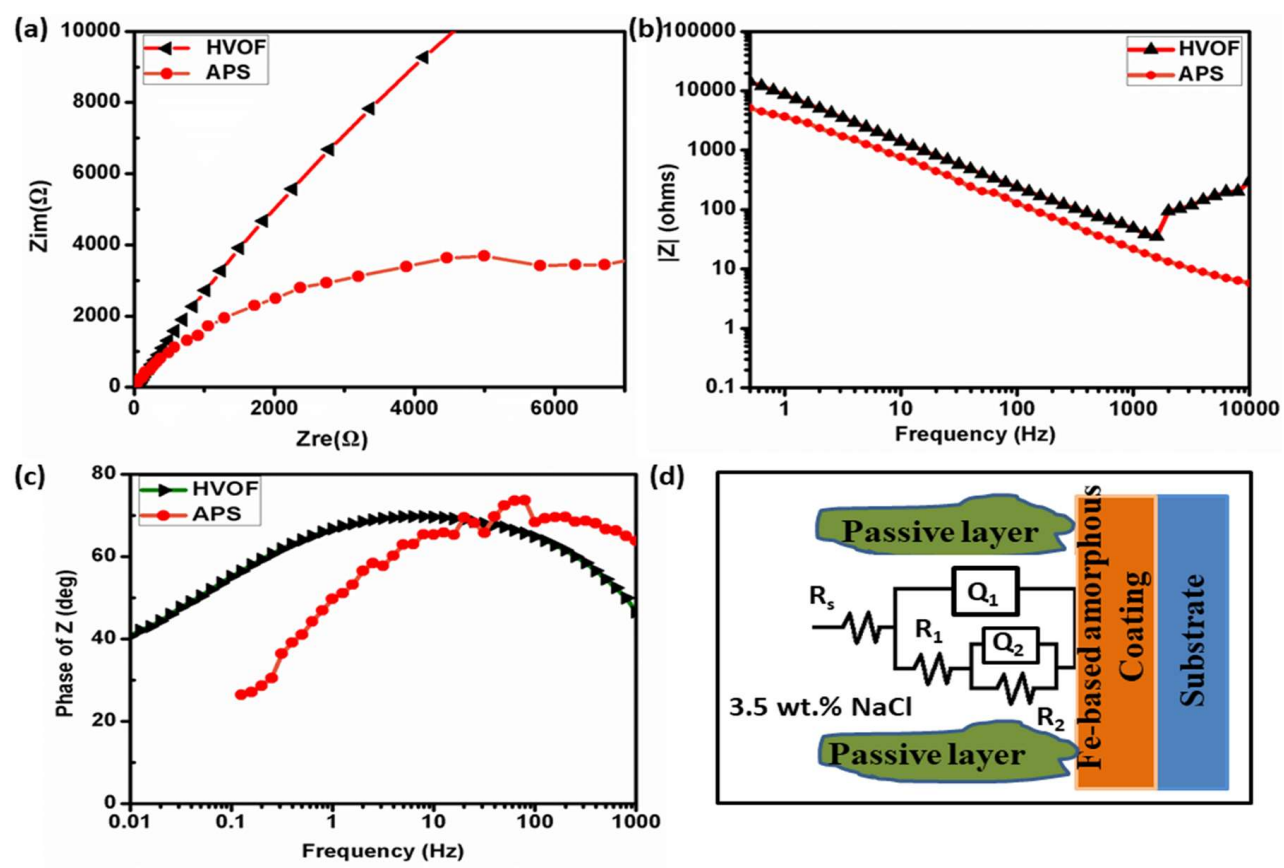

Figure 5. The electrochemical test results of SAM1651 in $3.5 \mathrm{wt} . \% \mathrm{NaCl}$ aqueous solution, coated by APS and HVOF. (a) Nyquist plot for APS and HVOF. (b) Bode plot. (c) Phase of Z (deg.) for APS and HVOF. (d) General model of the equivalent circuits proposed to carry out curve fitting for the EIS data from the Zsim 3.20 software. 
$R_{S}$ is the solution resistance by an electrolyte and $Q_{1}$ is the constant phase element for passive film, which is coupled with $R_{1}$. $Q_{2}$ is the ion flow, which works as passive film for electrolyte/metal oxide. $R_{2}$ is the charge-transfer resistance; the larger the $R_{2}$, the higher the corrosion resistance will be. It was observed that at low frequencies, the impedance behavior becomes a pure capacitor. Table 4 displays EIS results, which correlate with corrosion properties of both APS- and HVOF-coated samples. $R_{1}$ is parallel resistance to $Q_{1}$, which represents the polarization resistance for pitting. The larger the value of $R_{1}$, the lower the corrosion rate for pitting corrosion. Conversely, the lower the value of $R_{1}$, the higher the corrosion rate for pitting corrosion. The conclusion drawn from potentiodynamic and EIS results is that all the coatings offer higher resistance to corrosion compared to steel substrate.

Table 4. EIS-calculated values of equivalent circuit Zsim 3.20 software.

\begin{tabular}{cccccccc}
\hline EIS Sample & $\mathbf{R}_{\mathbf{s}}(\mathbf{o h m})$ & $\begin{array}{c}\text { CPE, Yo } \mathbf{Q}_{\mathbf{1}} \\
\left(\mathbf{S - s e c}^{\mathbf{n}}\right)\end{array}$ & $\mathbf{n}$ & $\mathbf{R}_{\mathbf{1}}(\mathbf{o h m})$ & $\begin{array}{c}\text { CPE, Yo } \mathbf{Q}_{\mathbf{1}} \\
\left.\mathbf{( S - s e c}^{\mathbf{n}}\right)\end{array}$ & $\mathbf{n}$ & $\mathbf{R}_{\mathbf{2}}(\mathbf{o h m})$ \\
\hline APS & 2.542 & $5.067 \times 10^{-5}$ & 0.7787 & 6153 & $8.648 \times 10^{-5}$ & 0.4121 & 6257 \\
HVOF & 6.389 & 0.001492 & 0.6447 & 4.335 & $8.139 \times 10^{-7}$ & 0.689 & 1790 \\
\hline
\end{tabular}

\subsection{Wear Studies}

\section{Tribometric Test}

The results of micro-Vickers hardness test elucidated that both the coatings produced by HVOF and APS show hardness in the range of 1100-1160 HV (Figure 6b). The hardness of the coatings obtained via APS is $3.9 \%$ less than the HVOF.
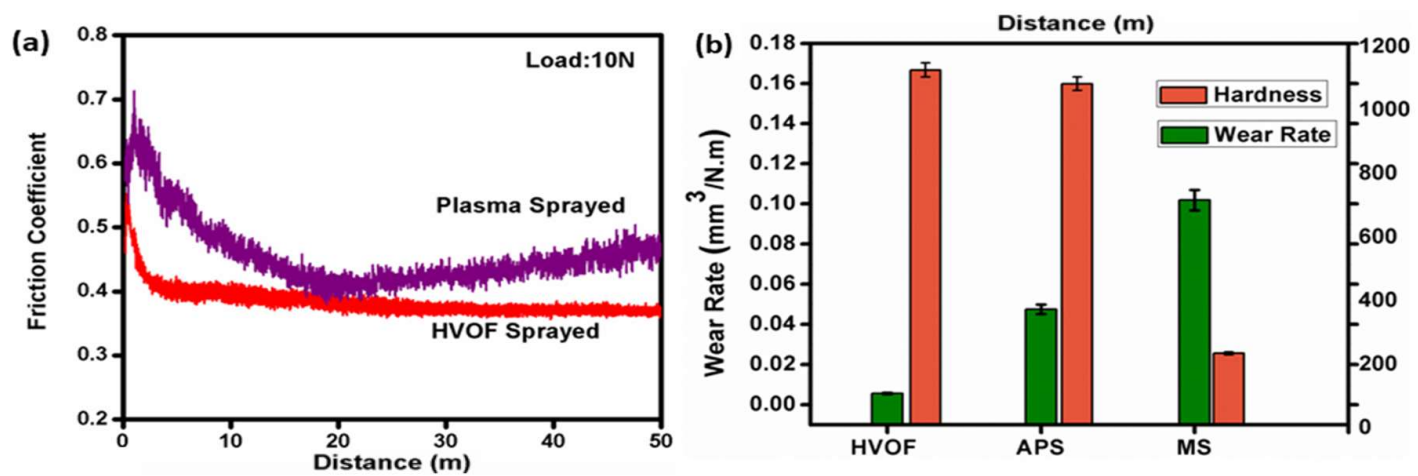

Figure 6. (a) Friction coefficient of iron-based amorphous coating. (b) Hardness and wear rate of iron-based amorphous coatings and steel substrate.

It is commonly observed that with the increase in spraying distance, the level of hardness starts to reduce. The hardness reduction in the coatings is attributed to the fact that by increasing the spray distance, the impact velocity of powder particles during spraying decreases which results in less compact coating and thus, lower hardness is achieved. Hardness is an important mechanical property of material which determines its resistance to tribo-corrosive environments [22]. It is interpreted that hardness of low-carbon steel can be increased by thermally sprayed, iron-based amorphous alloys [23,24]. The hardness obtained for the substrate is $227 \mathrm{HV}$, which is very low for load-bearing industrial applications. Table 5 compares some mechanical properties of bare and coated mild steel, which indicates that higher level of micro-Vickers hardness is achieved in HVOF-coated samples. 
Table 5. Tribometric and micro-Vickers results of substrate and iron-based amorphous coating.

\begin{tabular}{cccccc}
\hline $\begin{array}{c}\text { Bare and } \\
\text { Coated Samples }\end{array}$ & $\begin{array}{c}\text { Coating Thickness } \\
(\boldsymbol{\mu})\end{array}$ & Hardness (Hv) & $\begin{array}{c}\text { Accumulated Wear } \\
\text { Volume }\left(\mathbf{m m}^{\mathbf{3}}\right)\end{array}$ & Distance $(\mathbf{m})$ & $\begin{array}{c}\text { Wear Rate } \\
\mathbf{m m}^{\mathbf{3}} \mathbf{N}^{-\mathbf{1}} \mathbf{m}^{-\mathbf{1}}\end{array}$ \\
\hline HVOF & 302.96 & $1152 \pm 22.14$ & 0.001120428 & 50 & $\begin{array}{r}0.005602138 \\
( \pm 0.000112)\end{array}$ \\
\hline APS & 315.98 & $1107 \pm 23.04$ & 0.009491135 & 50 & $\begin{array}{r}0.047455677 \\
( \pm 0.000949)\end{array}$ \\
\hline MS & - & $227 \pm 4.5$ & 0.005092087 & 50 & $\begin{array}{r}1.01842 \times 10^{-5} \\
( \pm 0.00204)\end{array}$ \\
\hline
\end{tabular}

Wear and corrosion are the major problems faced by metallic surfaces. To alleviate these complications, electrolytic hard chrome coatings have been used in the past. But nowadays, iron-based amorphous coatings via thermal spray are an alternative way of protection. The specific wear rate was calculated by the equation given below:

$$
\mathrm{Q}=\mathrm{V}_{\mathrm{W}} /(\mathrm{NS}) \text {, }
$$

where $\mathrm{V}_{\mathrm{w}}$ is accumulated wear volume, $\mathrm{N}$ is load, and $\mathrm{S}$ is sliding distance. Wear rate has unit $\mathrm{mm}^{3} /(\mathrm{Nm})[24]$.

In this work, the friction coefficient and wear rate were determined to investigate the wear behavior of the developed coatings. Figure 6 a reveals the first increase of friction coefficient. The COF for HVOF first decreases, then remains constant; but in case of APS, it increases again and then stabilizes. This is due to different oxides and microscale defects in the APS coating which generate oscillations in the curve. There are various factors that decrease coating quality, for example, during thermal spraying techniques like in which oxygen and air are employed as combustor fuel. Oxidation of powder particles cannot be avoided; it forms oxygen-rich intersplat regions which decline the machine-driven performance of the coatings like wear and corrosion resistance issues.

The values obtained by wear rate are presented in Figure $6 b$, which reveal that iron-based amorphous coatings have anti-wear properties and can be applied for the protection of carbon steels in harsh environment. HVOF is found to have a lower friction coefficient and higher wear resistance than the counter APS-sprayed coatings. Anti-wear properties of three samples could be ranked as HVOF > APS > bare sample.

To investigate wear mechanism, SEM and EDS were performed for wear track and worn surfaces. Oxidative wear mechanism was observed by EDS analysis. Oxidation films are developed on samples due to atmospheric interference with the surface. The observed hardness of surface affects the development of oxidation films. The steel substrate has a low hardness value $(227 \mathrm{HV})$ and develops a higher amount of oxidation interference on its surface. In the case of APS and HVOF, the value of micro-Vickers hardness is higher, $1107 \pm 10 \mathrm{HV}$ and $1152 \pm 10 \mathrm{HV}$, respectively. The hard surface of iron-based amorphous coating (APS and HVOF) develops the least oxidation contents [25-27].

The micro-Vickers hardness of the coated films are approximately in the range of 1000-1200 HV. In this case, the above layer of oxidative particles protects the underlying layer from friction, and they support each other against damage. This process would continue if a film breaks and a new oxidative layer is formed after delamination. In the case of HVOF, this phenomenon is stronger due to higher micro-Vickers-hardness than APS [27].

Figure $7 \mathrm{a}, \mathrm{d}$ disclose the observation that slight delamination of the coating occurs in the case of HVOF. In the case of APS, due to microdefects and oxidation intersplats, heavy delamination is observed and confirms that HVOF has better wear-resistant properties. The depth of the wear track can be seen in HVOF. The EDS analysis revealed that the oxidation content in both the coatings was obvious, which confirms the oxidative mechanism in these results. This mechanism is compatible with previously published research [27-29]. It is noted that oxidation content in APS was higher than $\mathrm{HVOF}$, and the elements $\mathrm{Fe}, \mathrm{Cr}$, and Mo were least observed due to the highly compact surface of HVOF-coated sample. The wear track profile Figure $7 \mathrm{c}, \mathrm{f}$ indicates a $476 \mu \mathrm{m}$-track-width developed in 
the case of APS, and $170 \mu \mathrm{m}$ for HVOF. As the indenter moved, it damaged the highly oxidized region abruptly and increased the width of track.
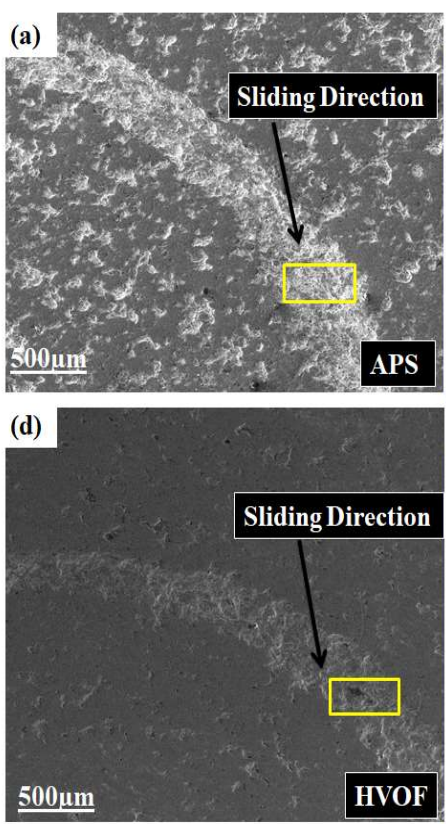
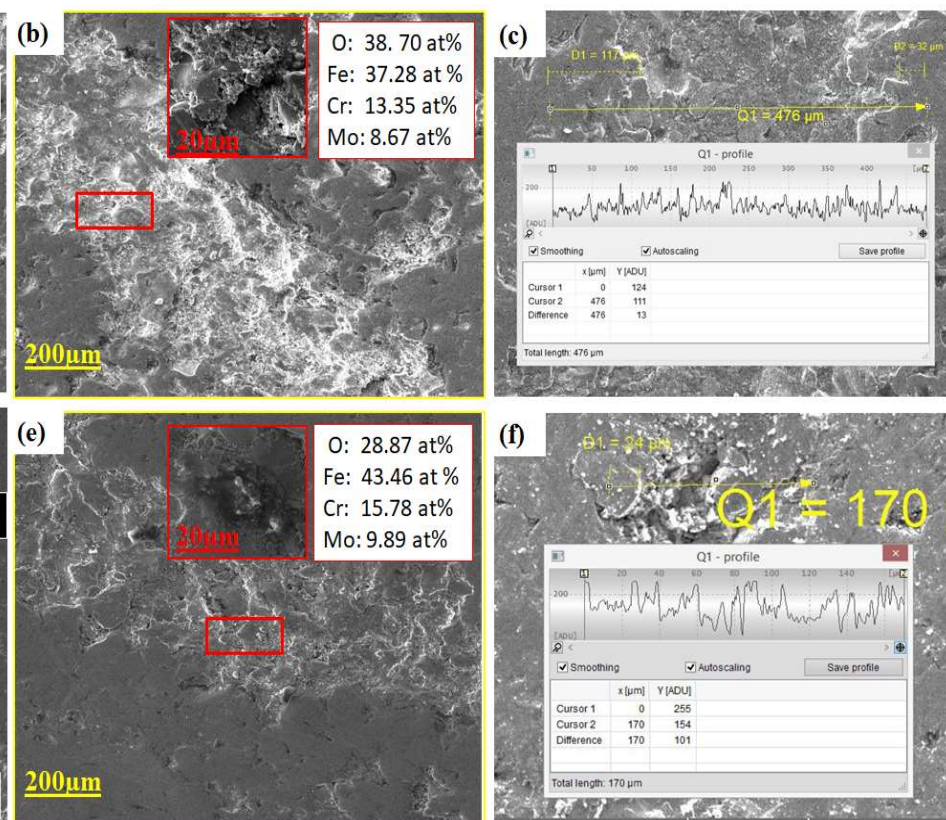

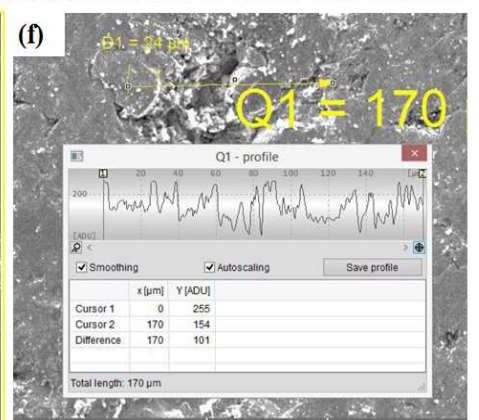

Figure 7. Wear track analysis (a,d). Sliding direction for APS and HVOF at 100× with $20.0 \mathrm{kv}(\mathbf{b}, \mathbf{e})$. Worn surface magnification at $300 \times$ with $20.0 \mathrm{kv}$. EDS was taken from insert image displayed at $20 \mu \mathrm{m}$ at $2.00 \mathrm{kx}$ with $20.0 \mathrm{kv}(\mathbf{c}, \mathbf{f})$. Wear track profile measurement for APS and HVOF.

The higher thickness of the coating would be more resistant but with least microdefects. It is investigated that thickness in APS is higher, but friction coefficient is more stable in the case of HVOF, which produced least worn-debris in wear track and confirmed better antiwear properties. It is also confirmed from wear volume loss, which indicates that the wear volume for HVOF-sprayed sample is the least.

\section{Conclusions}

The successful fabrication of iron-based amorphous alloy coatings was done by two different techniques. The dense amorphous structure was obtained for HVOF. The comparative analysis of the tribological properties of HVOF and APS shows that the HVOF-coated samples have better hardness and higher wear resistance. The electrochemical analysis of the samples shows that HVOF coated samples have better corrosion resistance in comparison to substrate and APS-coated samples. Hence, the corrosion and wear problem of low-carbon steel can be overcome by iron-based amorphous SAM1651 alloy. Hence, it can be concluded that the HVOF is a better technique to coat iron-based amorphous coatings. This work has potential applications in the aerospace, marine, and automobile industry.

Author Contributions: Conceptualization, M.Y.; Formal analysis, A.I. and S.S.; Funding acquisition, M.Y. and M.M.; Investigation, A.I.; Methodology, A.I., S.S., M.M. and M.Y.; Project administration, M.Y.; Resources, M.Y.; Visualization, M.A.U.R. and M.Y.; Writing-original draft, A.I.; Writing-review \& editing, M.Y., M.M. and M.A.U.R. All authors have read and agreed to the published version of the manuscript.

Funding: This work was financially supported by Higher Education commission Pakistan (HEC) under Technological development fund grant number HEC-TDF-02-046 and Pakistan Science Foundation (PSF/NSFC-II/ENG/C-IST (10)).

Conflicts of Interest: The authors declare no conflict of interest. 


\section{References}

1. Pang, S.J.; Zhang, T.; Asami, K.; Inoue, A. Synthesis of Fe-Cr-Mo-C-B-P bulk metallic glasses with high corrosion resistance. Acta Mater. 2002, 50, 489-497. [CrossRef]

2. Peng, Y.; Zhang, C.; Zhou, H.; Liu, L. On the bonding strength in thermally sprayed Fe-based amorphous coatings. Surf. Coat. Technol. 2013, 218, 17-22. [CrossRef]

3. Fu, B.-Y.; He, D.; Zhao, L. Effect of heat treatment on the microstructure and mechanical properties of Fe-based amorphous coatings. J. Alloys Compd. 2009, 480, 422-427. [CrossRef]

4. Zhang, C.; Liu, L.; Chan, K.C.; Chen, Q.; Tang, C.Y. Wear behavior of HVOF-sprayed Fe-based amorphous coatings. Intermetallics 2012, 29, 80-85. [CrossRef]

5. Vuoristo, P. Thermal Spray Coating Processes; Elsevier: Amsterdam, The Netherlands, 2014; Volume 4, ISBN 9780080965338.

6. Zhu, H.; Li, H. Microstructure Evolution of Thermally Sprayed TiB 2-Ni Cermet Coating: Comparison between APS and HVOF Process. J. Therm. Spray Technol. 2019, 28, 535-543. [CrossRef]

7. Liu, L.; Zhang, C. Fe-based amorphous coatings: Structures and properties. Thin Solid Films 2014, 561, 70-86. [CrossRef]

8. Huang, D.; Li, R.; Huang, L.; Ji, V.; Zhang, T. Fretting wear behavior of bulk amorphous steel. Intermetallics 2011, 19, 1385-1389. [CrossRef]

9. Guo, R.Q.; Zhang, C.; Yang, Y.; Peng, Y.; Liu, L. Corrosion and wear resistance of a Fe-based amorphous coating in underground environment. Intermetallics 2012, 30, 94-99. [CrossRef]

10. Qiao, L.; Wu, Y.; Hong, S.; Cheng, J.; Wei, Z. Influence of the high-velocity oxygen-fuel spray parameters on the porosity and corrosion resistance of iron-based amorphous coatings. Surf. Coat. Technol. 2019, 366, 296-302. [CrossRef]

11. Kumar, A.; Nayak, S.K.; Bijalwan, P.; Dutta, M.; Banerjee, A.; Laha, T. Optimization of mechanical and corrosion properties of plasma sprayed low-chromium containing Fe-based amorphous/nanocrystalline composite coating. Surf. Coat. Technol. 2019, 370, 255-268. [CrossRef]

12. Zhang, C.; Wu, Y.; Liu, L. Robust hydrophobic Fe-based amorphous coating by thermal spraying. Appl. Phys. Lett. 2012, 101, 1-5. [CrossRef]

13. Li, Y.C.; Zhang, C.; Xing, W.; Guo, S.F.; Liu, L. Design of Fe-Based Bulk Metallic Glasses with Improved Wear Resistance. ACS Appl. Mater. Interfaces 2018, 10, 43144-43155. [CrossRef] [PubMed]

14. Tillmann, W.; Schaak, C.; Hagen, L.; Mauer, G.; Matthäus, G. Internal Diameter Coating Processes for Bond Coat (HVOF) and Thermal Barrier Coating (APS) Systems. J. Therm. Spray Technol. 2019, 28, 233-241. [CrossRef]

15. Fatoba, O.S.; Akinlabi, S.A.; Akinlabi, E.T.; Gharehbaghi, R. Microstructural analysis, micro-hardness and wear resistance properties of quasicrystalline Al-Cu-Fe coatings on Ti-6Al-4V alloy. Mater. Res. Express 2018, 5. [CrossRef]

16. Cherigui, M.; Feraoun, H.I.; Feninehe, N.E.; Aourag, H.; Coddet, C. Structure of amorphous iron-based coatings processed by HVOF and APS thermally spraying. Mater. Chem. Phys. 2004, 85, 113-119. [CrossRef]

17. Wei, Y.K.; Li, Y.J.; Zhang, Y.; Luo, X.T.; Li, C.J. Corrosion resistant nickel coating with strong adhesion on AZ31B magnesium alloy prepared by an in-situ shot-peening-assisted cold spray. Corros. Sci. 2018, 138, 105-115. [CrossRef]

18. Ma, H.R.; Chen, X.Y.; Li, J.W.; Chang, C.T.; Wang, G.; Li, H.; Wang, X.M.; Li, R.W. Fe-based amorphous coating with high corrosion and wear resistance. Surf. Eng. 2017, 33, 56-62. [CrossRef]

19. Lutton Cwalina, K.; Demarest, C.R.; Gerard, A.Y.; Scully, J.R. Revisiting the effects of molybdenum and tungsten alloying on corrosion behavior of nickel-chromium alloys in aqueous corrosion. Curr. Opin. Solid State Mater. Sci. 2019, 23, 129-141. [CrossRef]

20. Mahata, N.; Banerjee, A.; Bijalwan, P.; Rai, P.K.; Sangal, S.; Mondal, K. Electrochemical Behavior of HVOF-Sprayed Amorphous and Nanocrystalline Fe-Based Fe73.13Si11.12B10.79Cr2.24C2.72 Composite Coatings. J. Mater. Eng. Perform. 2017, 26, 5538-5552. [CrossRef]

21. Zhang, C.; Guo, R.Q.; Yang, Y.; Wu, Y.; Liu, L. Influence of the size of spraying powders on the microstructure and corrosion resistance of Fe-based amorphous coating. Electrochim. Acta 2011, 56, 6380-6388. [CrossRef]

22. Yasir, M.; Zhang, C.; Wang, W.; Zhang, Z.; Liu, L. Tribocorrosion Behavior of Fe-Based Amorphous Composite Coating Reinforced by $\mathrm{Al}_{2} \mathrm{O}_{3}$ in $3.5 \% \mathrm{NaCl}$ Solution. J. Therm. Spray Technol. 2016, 25, 1554-1560. [CrossRef] 
23. Yasir, M.; Zhang, C.; Wei, W.; Liu, P.X.L. Wear behaviors of Fe-based amorphous composite coatings reinforced by $\mathrm{Al}_{2} \mathrm{O}_{3}$ particles in air and in $\mathrm{NaCl}$ solution. Mater. Des. 2015, 88, 207-213. [CrossRef]

24. Cheng, J.; Zhang, Q.; Feng, Y.; Zhao, S.; Liang, X. Microstructure and Sliding Wear Behaviors of Plasma-Sprayed Fe-Based Amorphous Coatings in 3.5 wt.\% $\mathrm{NaCl}$ Solution. J. Therm. Spray Technol. 2019, 28, 1049-1059. [CrossRef]

25. Stott, F.H.; Jordan, M.P. The effects of load and substrate hardness on the development and maintenance of wear-protective layers during sliding at elevated temperatures. Wear 2001, 250-251, 391-400. [CrossRef]

26. Xie, L.; Xiong, X.; Zeng, Y.; Wang, Y. The wear properties and mechanism of detonation sprayed iron-based amorphous coating. Surf. Coat. Technol. 2019, 366, 146-155. [CrossRef]

27. Wang, W.; Zhang, C.; Xu, P.; Yasir, M.; Liu, L. Enhancement of oxidation and wear resistance of Fe-based amorphous coatings by surface modification of feedstock powders. Mater. Des. 2015, 73, 35-41. [CrossRef]

28. Huang, B.; Zhang, C.; Zhang, G.; Liao, H. Wear and corrosion resistant performance of thermal-sprayed Fe-based amorphous coatings: A review. Surf. Coat. Technol. 2019, 377, 124896. [CrossRef]

29. Kovářík, O.; Haušild, P.; Siegl, J.; Pala, Z.; Matějíček, J.; Davydov, V. The influence of plasma sprayed multilayers of $\mathrm{Cr}_{2} \mathrm{O}_{3}$ and Ni10wt\%Al on fatigue resistance. Surf. Coat. Technol. 2014, 251, 143-150. [CrossRef]

Publisher's Note: MDPI stays neutral with regard to jurisdictional claims in published maps and institutional affiliations.

(C) 2020 by the authors. Licensee MDPI, Basel, Switzerland. This article is an open access article distributed under the terms and conditions of the Creative Commons Attribution (CC BY) license (http://creativecommons.org/licenses/by/4.0/). 